\title{
SENSITIVITY ANALYSIS OF ANGLE, LENGTH AND BRIM HEIGHT OF THE DIFFUSER FOR THE SMALL DIFFUSER AUGMENTED WIND TURBINE USING THE NUMERICAL INVESTIGATION
}

\author{
Yu Yu Maw ${ }^{1}$ and Min Thaw Tun ${ }^{2}$ \\ Department of Mechanical Engineering, Yangon Technological University, Yangon, Myanmar \\ ${ }^{1}$ Tel: +959420701918, e-mail: yunglelay@gmail.com \\ ${ }^{2}$ Tel: +959421022249, e-mail: minthaw@ytu.edu.mm
}

Received Date: October 31, 2019; Revised Date: June 12, 2021; December 8, 2021

\begin{abstract}
This paper presents the performance of the diffuser augmented wind turbine (DAWT) with the various diffuser shapes using the numerical investigations. DAWT is also a type of wind turbine and the diffuser shapes, the nozzle shapes and the cylindrical shapes are commonly inserted around the horizontal axis wind turbine (HAWT) to become the more efficient wind turbine. The aim of this study is to find the more efficient design of the diffuser for the horizontal axis wind turbine using the numerical investigations. In this research, the converging and diverging diffuser shape is inserted and the airfoil design is calculated by using the Blade Elementary Momentum Theory. The airfoil type NACA 4412 is chosen because it is suitable for the low wind speed area and easy to produce. The turbulent model k- $\omega$ is combined with the Navier Stoke equation to solve the 3-dimensional steady flow simulation of the diffuser augmented wind turbine using the Computational Fluid Dynamics (CFD) simulations. The numerical investigation is used to compare and predict the power coefficient of the DAWT with various shapes. The baseline design of the diffuser $(\mathrm{L}=170$ $\mathrm{mm}, \mathrm{H}=57 \mathrm{~mm}$ and $\alpha=11^{\circ}$ ) is firstly investigated. To predict the power coefficient of the various diffuser shapes, the range of the length of the diffuser is ( $\mathrm{L} / \mathrm{D}=0.5$ to 1.5$)$, the range of the brim height of the diffuser $(\mathrm{H} / \mathrm{D}=0.1$ to 0.35$)$ and the range of the angle of the diffuser $\left(\alpha=5^{\circ}\right.$ to $\left.15^{\circ}\right)$ are also investigated. The parameters of the diffuser shapes are assigned by using the Central Composite Design Face Centered Method. The response surface method is also used to predict the most efficient diffuser design. The performance of the horizontal axis wind turbine, that of the diffuser augmented wind turbine and that of the diffuser augmented wind turbine with various shapes of diffuser are compared. The performance of new diffuser augmented wind turbine (IND_009) is 50\% and 55\% higher than the baseline diffuser augmented wind turbine and the horizontal axis wind turbine at rated velocity. The flow visualization of the HAWT, DAWTs are also discussed.
\end{abstract}

Keywords: Airfoil, Brim height, Diffuser augmented wind turbine, Power coefficient

\section{Introduction}

Nowadays, the energy demand in the world is significantly getting greater. To get great competitive economic growth and create higher living standards, the energy is the main requirement for every country. To cover this requirement, wind energy technologies have developed rapidly because the wind is a free, clean and inexhaustible renewable resource for energy production. 
Y. Ohya et al [1] presented the efficient wind turbine with the broad-ring brim at the exit of the wind turbine and the power from this turbine is 2 to 5 times more efficient than the bare wind turbine. O. Igra [2] investigated the wind turbines with the shroud which is compact and give the efficient power. The area of the diffuser divergence causes the flow separation and output power reduction. To overcome this problem, proper diversion and the external flow of shroud into the inner layer of the diffuser are achieved. B. Kosasih, et al [3] studied the experiment of the shrouded micro wind turbine with the various diffuser lengths and flange heights to find the reliable wind turbine which gives the better performance in the suitable location. S. Zanforlin et al [4] emphasized to improve the efficiency of the wind turbines in urban area by adding the diffuser shape around the turbine and placing the turbine at the rooftops. Y. Ohya et al [5] investigated the wind lens technology application for wind and water turbines and multi-rotors design of wind lens turbine generates more total power output. F. Sorribes-Palmer et al [6] presented the design optimization of the wind turbine diffuser by using the 1D CFD simulations to compare the thrust coefficient with the experimental results. B. Kanya et al [7] validated the numerical simulation of the ducted wind turbine with experiment and it was found that the twice of power output at the same velocity. N.A. Pambudi et al [8] studied the conducting of shrouded wind turbine with the various inlet shrouds and without the shrouds to become the more output turbine for the low wind speed areas.

In this paper, the various diffuser designs (15 designs) generated from the central composite design face centered method will be investigated by computational fluid dynamics (CFD). Then, the sensitivity analysis of the diffuser's length, the brim height and the angle of the diffuser on the power coefficient at the same velocity and revolution will be discussed according to the torque from the results of the CFD. The more efficient diffuser shape for the wind turbine is also predicted.

\section{Research Background}

The three-dimensional model of the rotor of the horizontal axis wind turbine is as shown in Figure 1. The diameter of the rotor is $300 \mathrm{~mm}$, the revolution of the rotor is $2800 \mathrm{rpm}$ and the cut-in velocity, rated velocity and cut out velocity are $7 \mathrm{~m} / \mathrm{s}, 9 \mathrm{~m} / \mathrm{s}$ and $13.5 \mathrm{~m} / \mathrm{s}$ respectively. The BEM calculation is applied to compare the performance of the horizontal axis wind turbine with the twisted blade and tapered blade. Numerical simulations were validated with the calculations result for three different wind velocities as shown in Figure $2[9]$.

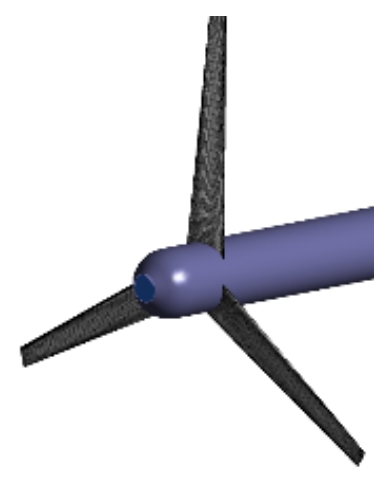

(a) Rotor

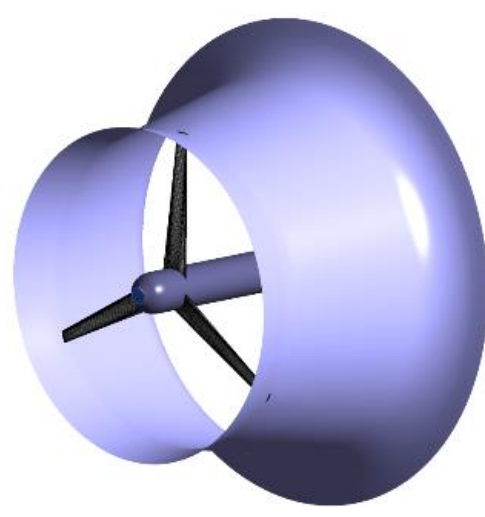

(b) Rotor with the diffuser

Figure 1. Rotor of the diffuser augmented wind turbine 
In the previous research [10], the baseline design of the diffuser is mounted around the rotor to become more efficient wind turbine. The parameters of the baseline design of the diffuser range of chosen parameters for sensitivity analysis are shown in Table 1 . The performance of the DAWT is $25 \%$ higher than that of the HAWT and maximum power coefficient is occurred at the rated wind velocity $9 \mathrm{~m} / \mathrm{s}$; the tip speed ratio is 5 in this velocity for two types of the wind turbines.

Table 1. The Parameters of the Diffuser Design [10]

\begin{tabular}{|c|c|c|c|c|}
\hline \multirow{2}{*}{ No. } & \multirow{2}{*}{ Parameter } & \multicolumn{3}{|c|}{ Dimensions } \\
\hline & & Baseline & Maximum & Minimum \\
\hline 1. & Rotor diameter $\left(\mathrm{D}_{\text {rotor }}\right)$ & $300 \mathrm{~mm}$ & - & - \\
\hline 2. & Throat diameter $\left(\mathrm{D}_{\text {throat }}\right)$ & $310 \mathrm{~mm}$ & - & - \\
\hline 3. & Exit diameter $\left(\mathrm{D}_{\mathrm{e}}\right)$ & $370 \mathrm{~mm}$ & - & - \\
\hline 4. & Length of the diffuser (L) & $170 \mathrm{~mm}$ & $450 \mathrm{~mm}$ & $150 \mathrm{~mm}$ \\
\hline 5. & Diffuser angle $(\alpha)$ & $11^{\circ}$ & $5^{\circ}$ & $15^{\circ}$ \\
\hline 6. & Brim Height of the diffuser $(\mathrm{H})$ & $57 \mathrm{~mm}$ & $105 \mathrm{~mm}$ & $30 \mathrm{~mm}$ \\
\hline 7. & $\begin{array}{l}\text { Length of the inlet section of the } \\
\text { diffuser (1) }\end{array}$ & $45 \mathrm{~mm}$ & - & - \\
\hline
\end{tabular}

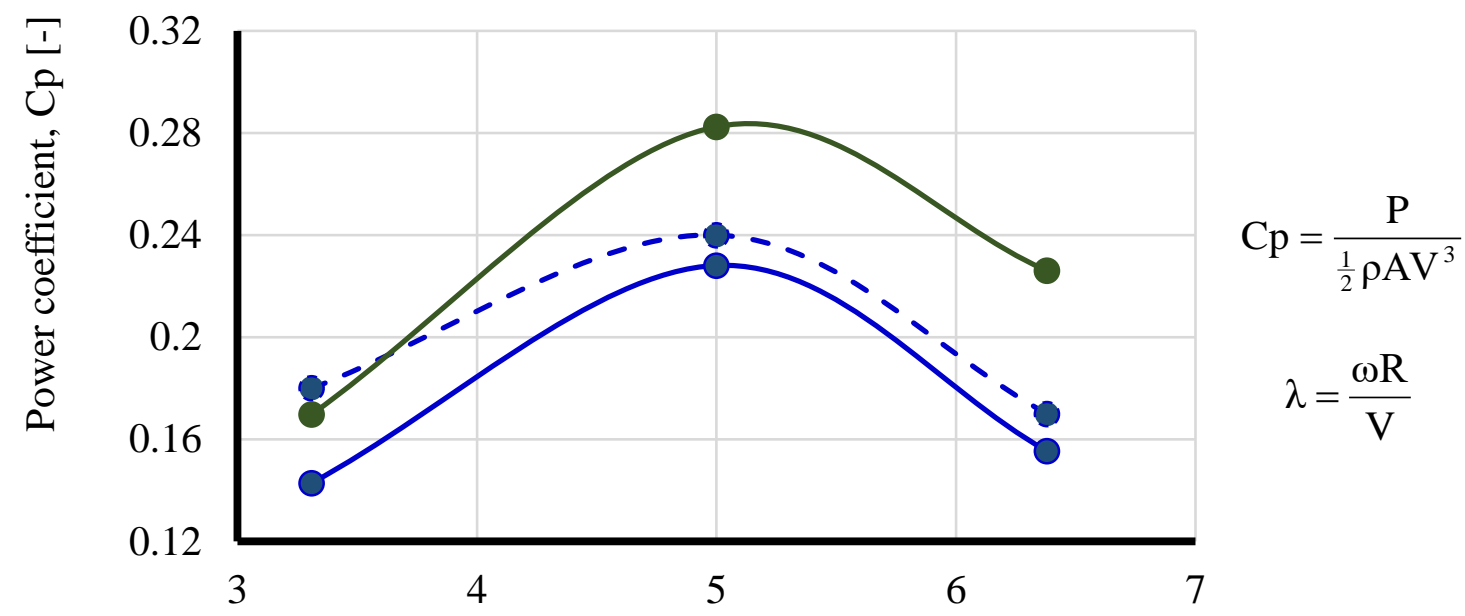

Tip speed ratio, $\lambda[-]$

- - HAWT (BEM) - —HAWT (CFD) - - Baseline DAWT

Figure 2. Performance comparison between DAWT and HAWT and validation of CFD (HAWT)

The $\mathrm{x}$-axis represents the tip speed ratio $\lambda$, which is a ratio of the velocity of the rotor tip and the wind velocity. The y-axis represents the power coefficient of the wind turbine which can be defined as the ratio of the generated power and the power in the wind as shown in Figure 2. 
The blue dashed line is the performance curve of the HAWT for BEM calculation. The maximum power coefficient is 0.24 at the rated velocity for the BEM calculation of the HAWT. The blue solid line is the performance curve of the HAWT for numerical simulation. The maximum power coefficient is about 0.23 at the rated velocity for the numerical simulation of the HAWT. Therefore, the discrepancy error of the power coefficient for the HAWT is only $4 \%$ and it can be assumed that the simulation is well agreed with the BEM calculation. According to the simulation results, the diffuser augmented wind turbine is $21 \%$ more efficient than the horizontal axis wind turbine at the rated velocity $9 \mathrm{~m} / \mathrm{s}$.

\section{Methods}

\section{Geometry of the Diffuser}

The geometry of the diffuser for the diffuser augmented wind turbine is shown in Figure 3. This geometry is constructed by 7 parameters in this diffuser structure such as the brim height of the diffuser $(\mathrm{H})$, the length of the diffuser $(\mathrm{L})$, the angle of the diffuser $(\alpha)$, the throat diameter $\left(D_{\text {throat }}\right)$, the rotor diameter $\left(D_{\text {rotor }}\right)$, the diameter of the exit of the diffuser $\left(D_{e}\right)$ and the length of the inlet section of the diffuser (1).

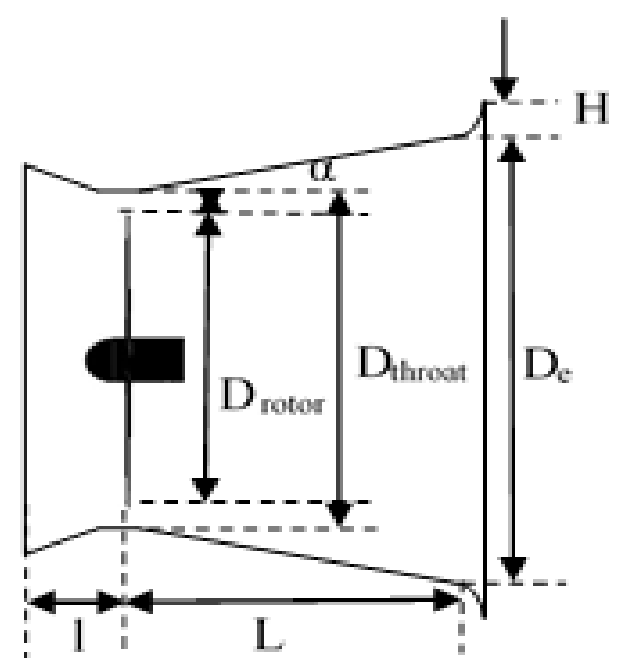

Figure 3. The geometry of the diffuser

\section{Design of Experiments (DOE)}

To determine the interaction between the input parameters and output result of the process, design of experiments (DOE) is used. It is needed to specify the problem and select the variables, which are termed factors or parameters [10].

In this research, 3 parameters of the diffuser are selected to analyse the sensitivity such as the length of the diffuser $(\mathrm{L})$, the brim height of the diffuser $(\mathrm{H})$ and the angle of the diffuser $\alpha$. The range of 3 parameters are the length of the diffuser ( $\mathrm{L} / \mathrm{D}=0.5$ to 1.5$)$, the brim height of the diffuser $(H=0.1$ to 0.35$)$ and the angle of the diffuser $(\alpha=5$ to 15$)$. The output of the numerical investigations is power coefficient $(\mathrm{Cp})$, for all diffuser designs.

To construct the various parameters of the diffuser, the central composite face centered methods is applied, according to the assigned ranges of the length of the diffuser, the brim height of the diffuser and angle of the diffuser. By applying this method, there are 15 diffuser designs and these designs are called individual (IND) designs. Therefore, CFD analyses are carried out for these 15 samples diffuser design [11]. 
Table 2. RSM Design Parameters

\begin{tabular}{cccccc} 
& Coded & \multicolumn{3}{c}{ Uncoded } \\
\hline $\mathbf{H}$ & $\boldsymbol{\alpha}$ & $\mathbf{L}$ & $\mathbf{H}(\mathbf{m m})$ & $\boldsymbol{\alpha}\left({ }^{\circ}\right)$ & $\mathbf{L}(\mathbf{m m})$ \\
\hline 0 & 0 & 0 & 67.5 & 10 & 300 \\
-1 & -1 & -1 & 30 & 5 & 150 \\
-1 & -1 & 1 & 30 & 5 & 450 \\
-1 & 1 & -1 & 30 & 15 & 150 \\
1 & 1 & 1 & 30 & 15 & 450 \\
1 & -1 & -1 & 105 & 5 & 150 \\
1 & -1 & 1 & 105 & 5 & 450 \\
1 & 1 & -1 & 105 & 15 & 150 \\
1 & 1 & 1 & 105 & 15 & 450 \\
-1 & 0 & 0 & 105 & 10 & 300 \\
0 & 0 & 0 & 30 & 10 & 300 \\
0 & 1 & 0 & 67.5 & 15 & 300 \\
0 & -1 & 0 & 67.5 & 5 & 300 \\
0 & 0 & -1 & 67.5 & 10 & 150 \\
& 0 & 1 & 67.5 & 10 & 450 \\
\hline
\end{tabular}

\section{CFD Simulations and Boundary Set up}

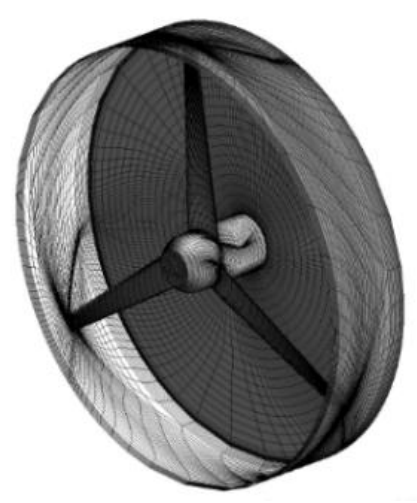

(a) Mesh generation of HAWT

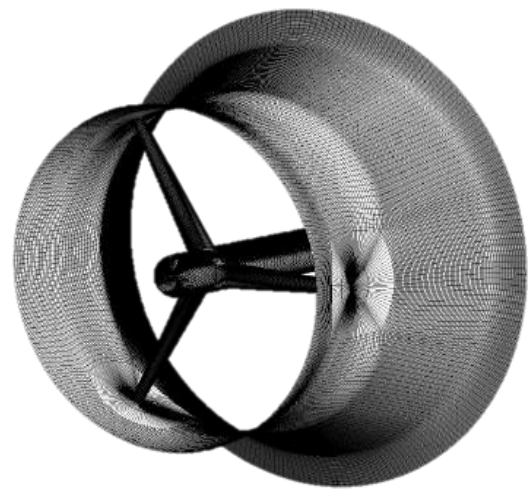

(b) Mesh generation of DAWT

Figure 4. Mesh generation of the rotating domain

The numerical simulations with the steady state condition are investigated by using the commercial CFD code of ANSYS-CFX. The combination of Low Reynold's number $\left(1.58 \times 10^{4}\right)$ and the turbulent model $\mathrm{k}-\omega$ is applied in this flow investigation. 


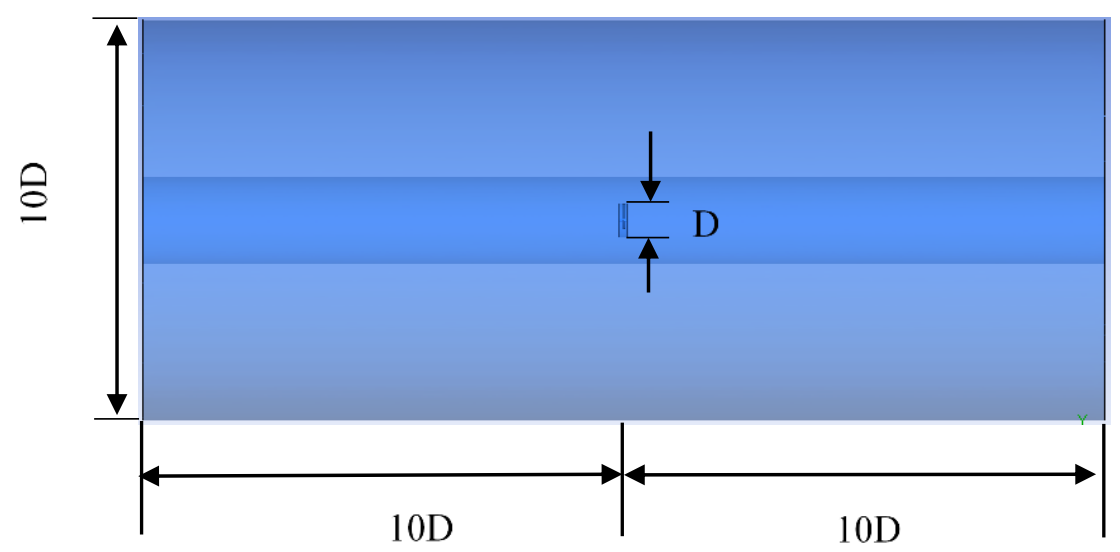

Figure 5. Dimensions of the stationary domain

There are two domains in this numerical investigation such as the rotating domain and stationary domain. The mesh generation of the rotating domain is created in the ANSYS Turbogrid. The number of mesh of rotating domain for the horizontal axis wind turbine is nearly 0.3 million and that of the diffuser augmented wind turbine is nearly 0.45 million as shown in Figure 4. The mesh type for two turbines is the hexahedra.

The cylindrical shape is used as the stationary domain and the dimensions of this domain are $10 \mathrm{D}$ for the upstream and downstream of the rotor and $10 \mathrm{D}$ for the outer region. The geometry of the stationary domain is shown in Figure 5 and the mesh generation of that domain is shown in Figure 6. The stationary mesh for two types of wind turbines are generated in the ICEM and the number of mesh of stationary domain for two turbines is nearly 16 million. The two domains are connected by using the frozen rotor interface.

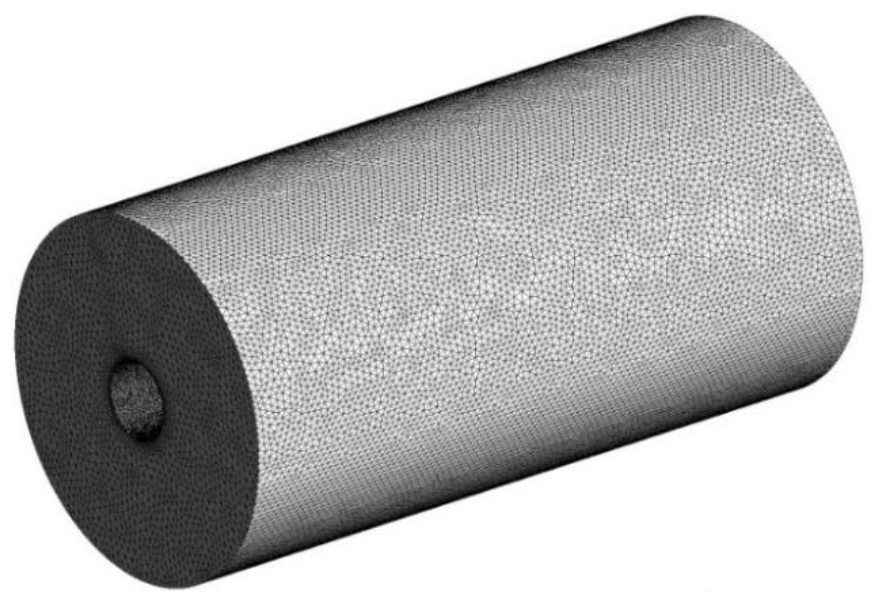

Figure 6. Mesh generation of the stationary domain

For the numerical investigation, the air is assigned as the working fluid and the atmospheric pressure and the temperature are $1 \mathrm{~atm}$ and $300^{\circ} \mathrm{K}$, respectively. For all numerical simulations, RMS residual levels of $1 \times 10^{-4}$ were considered. In the inlet stationary boundary, the inlet velocity $(9 \mathrm{~m} / \mathrm{s})$ is applied and the static pressure $(0 \mathrm{~Pa})$ is set at the outlet stationary boundary. The revolution of the rotor is $2800 \mathrm{rpm}$. The blades are assigned as the rotating wall for two types of turbines. The outer stationary domain is assigned as the no slip wall condition. The boundary set up of the diffuser augmented wind turbine are same as that of the horizontal axis wind turbine excepting the condition of the shroud (diffuser), where shroud is regarded as the interface in horizontal axis wind turbine and which is set up as the wall in diffuser augmented wind turbine. 


\section{Results and Discussions}

\section{Sensitivity Analysis of the Diffuser's Parameters as a Function of Power Coefficient}

Table 3 shows the numerical simulation result of the power value and the maximum power (17.67 Watt) is occurred at the design IND_009. The parameters of this diffuser are L/D = $1, \mathrm{H} / \mathrm{D}=0.35$ and $\alpha=10^{\circ}$ in IND_009 diffuser design. According to this simulation results, it is needed to guess the most efficient design of the diffuser.

In Figure 7, the 2-dimensional the sensitivity analysis of the length of the diffuser on the power coefficient is presented. The numerical simulations of diffuser augmented wind turbines have been investigated with the length of the diffuser range between $L / D=0.5$ to 1.5. Among them, the maximum power coefficient is occurred at the length of $(\mathrm{L} / \mathrm{D}=1)$. The power coefficient is about 0.56 , therefore the power output for this design from the numerical simulation is $8.91 \mathrm{~W}$ att.

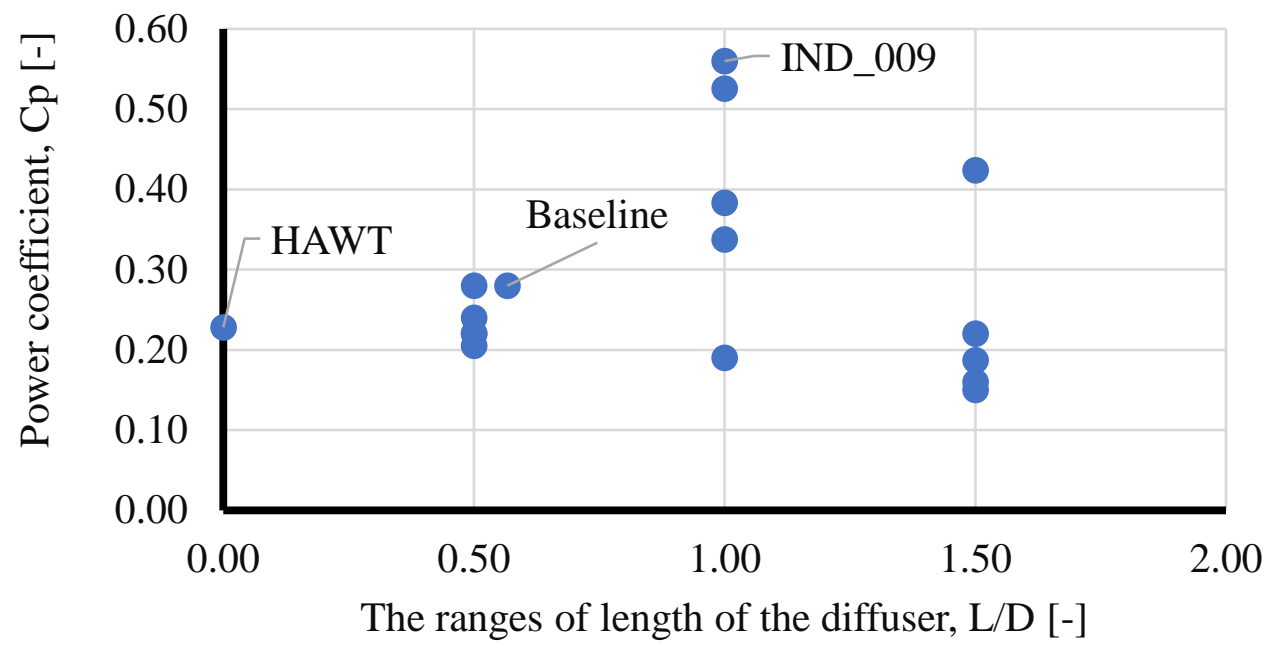

Figure 7. Sensitivity analysis of diffuser's length on power coefficient

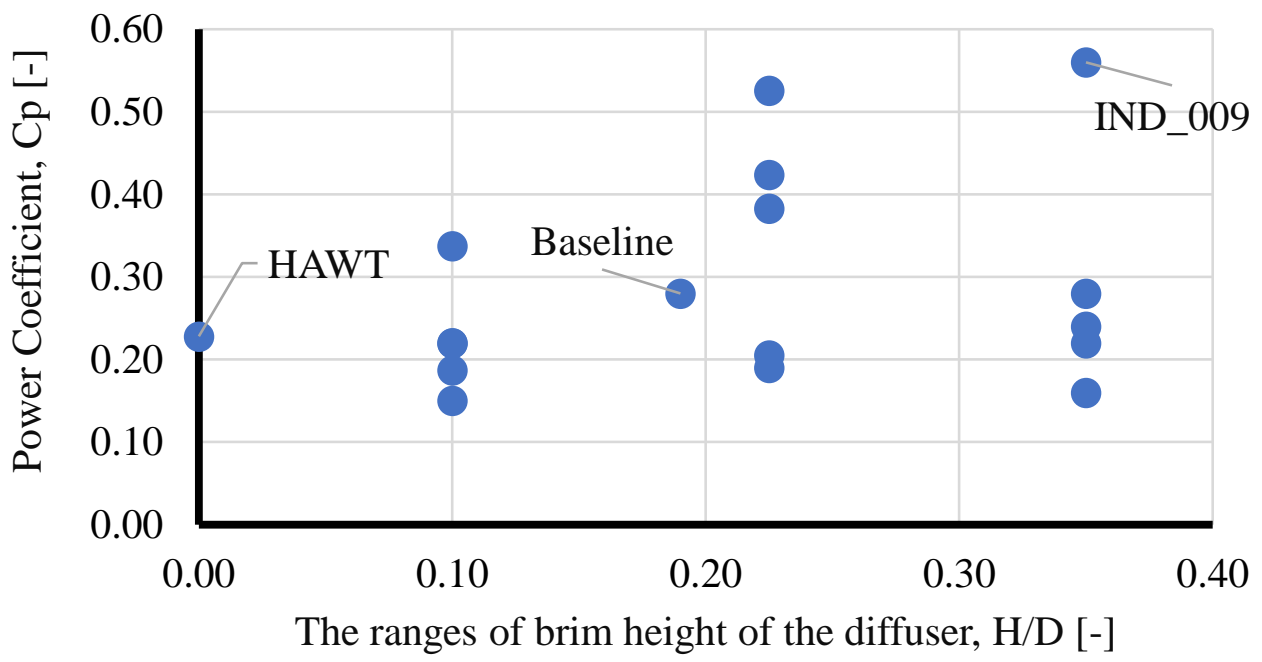

Figure 8. Sensitivity analysis of the brim height of the diffuser on power coefficient 
Table 3. Power Generating from the Various Diffuser Designs

\begin{tabular}{cccccc}
$\begin{array}{c}\text { Individual } \\
\text { Design }\end{array}$ & $\begin{array}{c}\text { H } \\
{[\mathbf{m m}]}\end{array}$ & $\begin{array}{c}\text { Angle } \\
\text { [Degree] }\end{array}$ & $\begin{array}{c}\text { L } \\
{[\mathbf{m m}]}\end{array}$ & $\begin{array}{c}\text { Power } \\
{[\text { Watt] }}\end{array}$ & $\begin{array}{c}\text { Cp } \\
{[-]}\end{array}$ \\
\hline Baseline & 57 & 11 & 170 & 8.91 & 0.19 \\
IND_000 & 67.5 & 10 & 300 & 5.91 & 0.22 \\
IND_001 & 30 & 5 & 150 & 6.98 & 0.15 \\
IND_002 & 30 & 5 & 450 & 4.88 & 0.22 \\
IND_003 & 30 & 15 & 150 & 7.00 & 0.19 \\
IND_004 & 30 & 15 & 450 & 5.90 & 0.24 \\
IND_005 & 105 & 5 & 150 & 7.44 & 0.16 \\
IND_006 & 105 & 5 & 450 & 4.92 & 0.28 \\
IND_007 & 105 & 15 & 150 & 8.86 & 0.22 \\
IND_008 & 105 & 15 & 450 & 6.86 & 0.56 \\
IND_009 & 105 & 10 & 300 & 17.67 & 0.19 \\
IND_010 & 30 & 10 & 300 & 10.65 & 0.53 \\
IND_011 & 67.5 & 15 & 300 & 16.59 & 0.38 \\
IND_012 & 67.5 & 5 & 300 & 12.09 & 0.21 \\
IND_013 & 67.5 & 10 & 150 & 6.48 & 0.42 \\
IND_014 & 67.5 & 10 & 450 & 13.38 & 0.19 \\
\hline
\end{tabular}

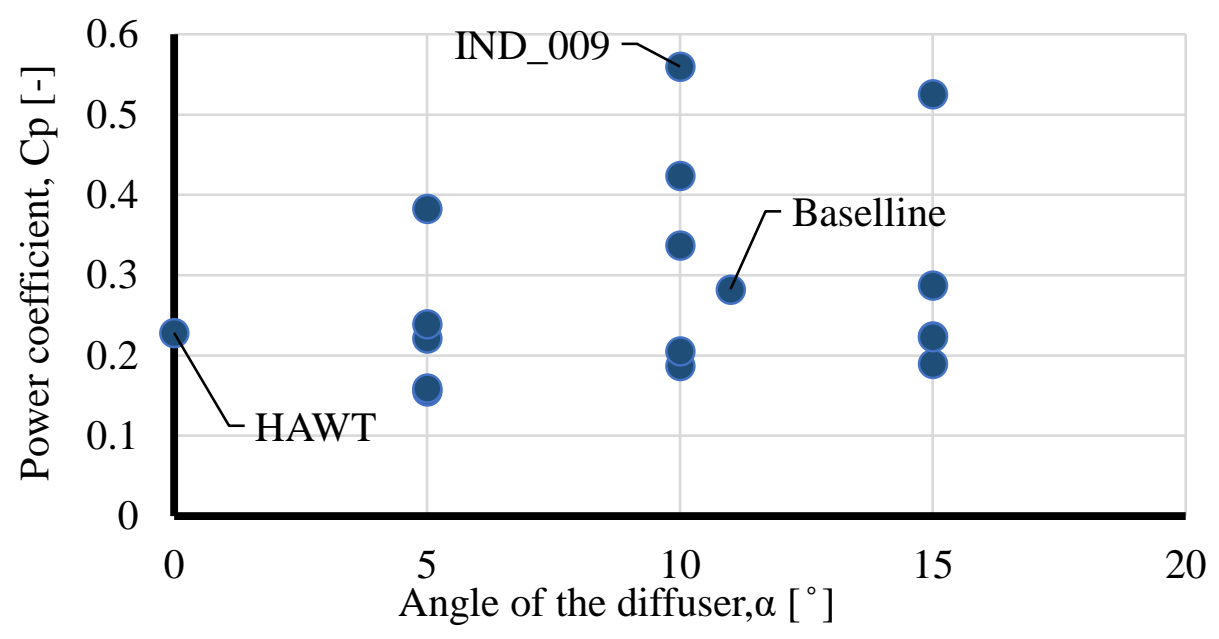

Figure 9. Sensitivity analysis of the angle of the diffuser on power coefficient

Figure 8 also shows the 2-dimensional sensitivity analysis of the brim height of the diffuser on the power coefficient. The range of the brim height of the diffuser is between $\mathrm{H} / \mathrm{D}=0.1$ to 0.35 in these simulations and the maximum power coefficient is occurred at the brim height of $\mathrm{H} / \mathrm{D}=0.35$. 
The sensitivity analysis of the angle of the diffuser on the power coefficient is shown in Figure 9. The range of the angle of the diffuser between $\alpha=5^{\circ}$ to $15^{\circ}$ are numerically investigated. The maximum power coefficient is occurred when the angle of diffuser is $10^{\circ}$.

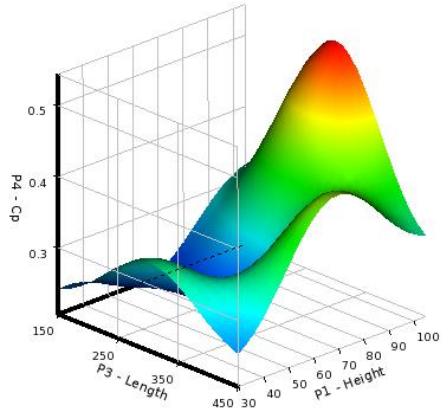

(a) Power coefficient with length and brimmed height

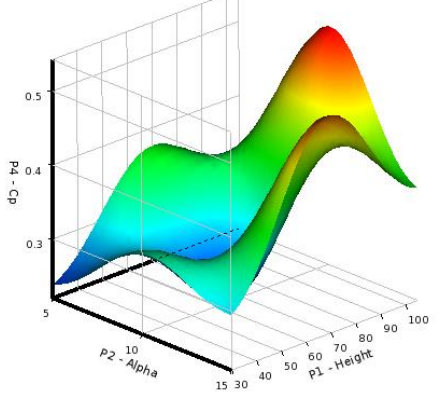

(b) Power coefficient with angle

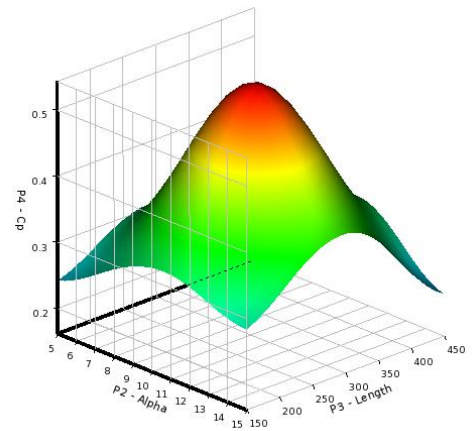

(c) Power coefficient with length and angle

Figure 10. Power coefficient with length, brimmed height and angle of the diffuser by response surface graph

According to this analysis, when the brim height of the diffuser is higher, the performance of the diffuser become higher because more wake region is created behind the diffuser. Therefore, the parameters of the diffuser which can generate the maximum power coefficient are the length of the diffuser L/D is 1, the brim height of the diffuser H/D is 0.35 and the angle of the diffuser $\alpha$ is $10^{\circ}$, according to those sensitivity analyses.

It is also applied the response surface method to predict the most efficient diffuser shape for the diffuser augmented wind turbine. According to the response surface graph, it is also show that the parameters of the most efficient diffuser shape are nearly occurred at the length of the diffuser L/D is 1, the brim height of the diffuser H/D is 0.35 and the angle of the diffuser $\alpha$ is $10^{\circ}$ as shown in Figure 10. Therefore, the parameters of the diffuser from the numerical simulations result can be reasonable and reliable.

\section{Performance Comparison and Flow Visualization of the HAWT, Baseline DAWT and IND_009 DAWT}

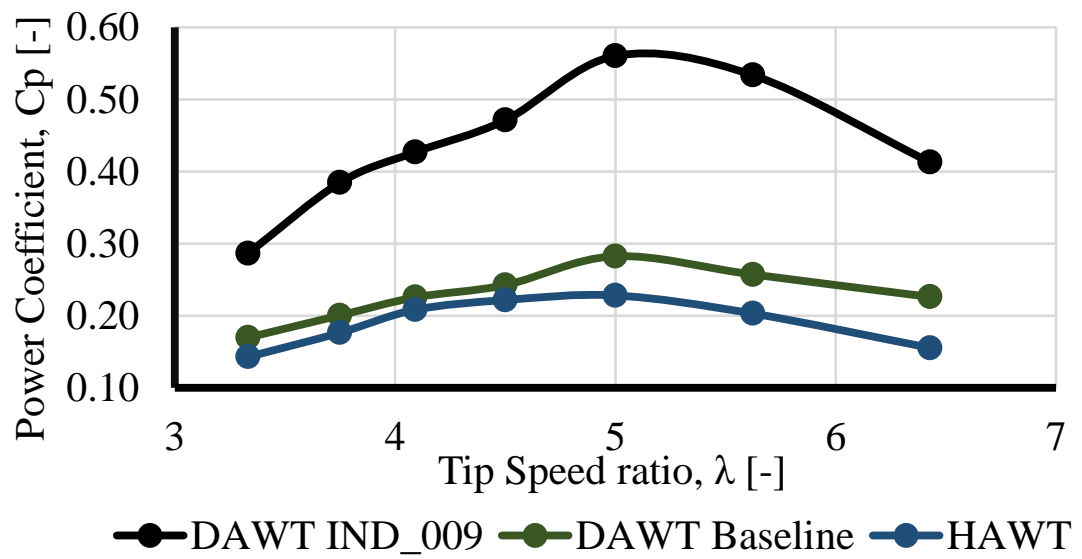

Figure 11. Performance comparison of HAWT, baseline DAWT and IND_009 
The performance comparison of the horizontal axis wind turbine, the diffuser augmented wind turbine with the baseline diffuser design and the diffuser augmented wind turbine with IND_009 diffuser design under different velocities (from 9 to $13.5 \mathrm{~m} / \mathrm{s}$ ) are shown in Figure 11. The maximum power coefficient is occurred at the rated velocity for all three types of wind turbines. The diffuser augmented wind turbine with the baseline diffuser is more efficient than that of horizontal axis wind turbine [12]. The performance of diffuser augmented wind turbine with the IND_009 diffuser design is 50\% and 55\% higher than the diffuser augmented wind turbine with the baseline diffuser design and the horizontal axis wind turbine at rated velocity $[9 \mathrm{~m} / \mathrm{s}]$. For the cut-in velocity $[7 \mathrm{~m} / \mathrm{s}]$, the performance of the IND_009 diffuser design is 53\% and 67\% higher than the baseline diffuser design and the horizontal axis wind turbine. It can also be seen that the performance of the IND_009 diffuser design is $43 \%$ and $53 \%$ more efficient than the baseline diffuser design and the horizontal axis wind turbine at the cut-out velocity $[13.5 \mathrm{~m} / \mathrm{s}]$.

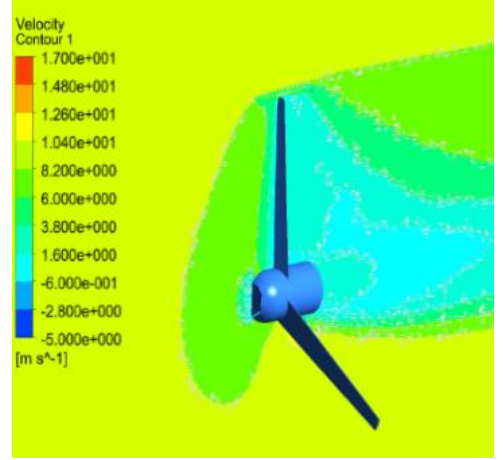

(a) HAWT

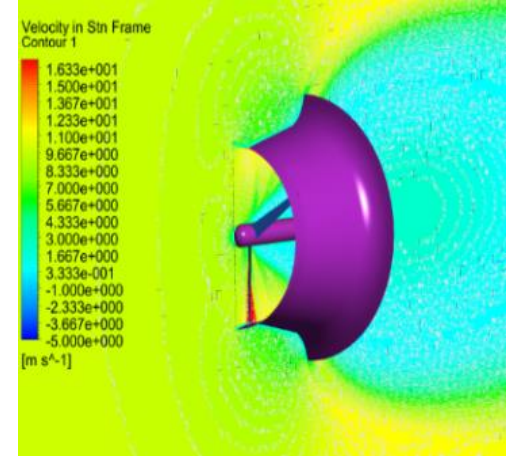

(b) Baseline diffuser design

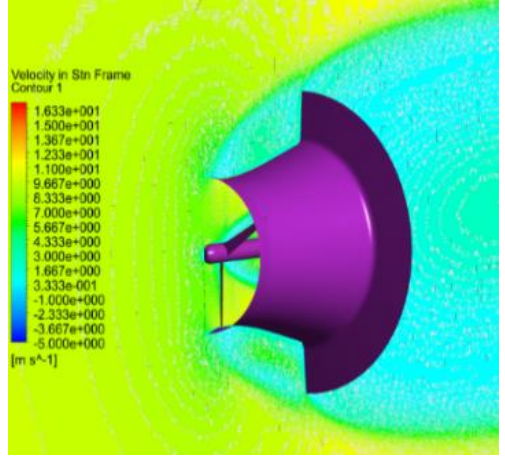

(c) IND_009 diffuser design

Figure 12. Velocity contours of the wind turbines

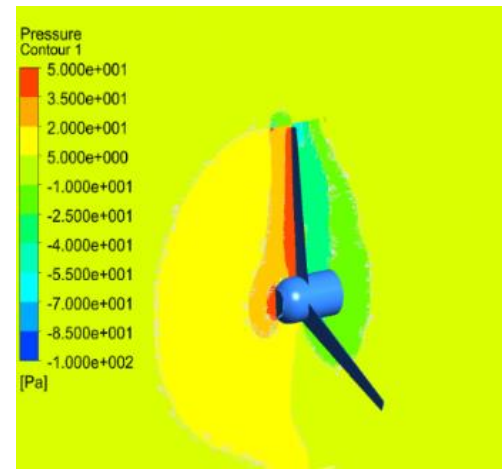

(a) HAWT

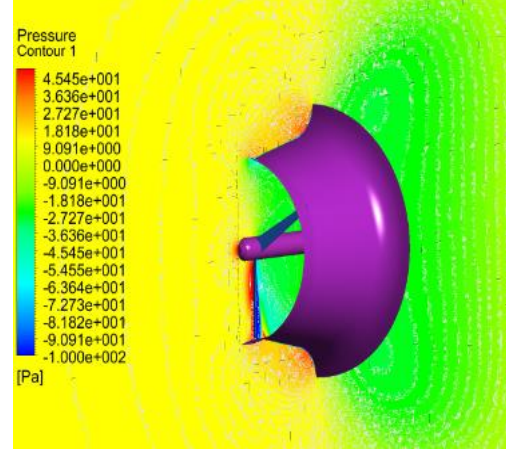

(b) Baseline diffuser design

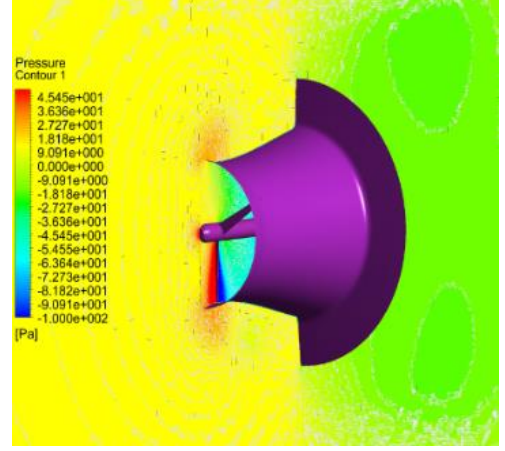

(c) IND_009 diffuser design

Figure 13. Pressure contours of the wind turbines

The flow phenomena around the wind turbines from the numerical simulations are shown in Figure 12 and Figure 13. From the velocity contours, it is occurred that the larger wake formation which creates a low-pressure zone after the diffuser. The pressure before the blade is higher than the pressure after the blade. More air flow is suck into the diffuser because of this low-pressure zone and that air flow quickly turns the turbine to produce the higher torque. In the velocity contour of IND_009 diffuser design, larger wake region can be seen because of the brim height of the diffuser. 


\section{Conclusions}

Based on the sensitivity analysis of the length of the diffuser, the brim height of the diffuser and angle of the diffuser on the power coefficient, the maximum power coefficient is occurred at the IND_009 diffuser design. When the length of the diffuser is too longer, the performance will decrease. And the brim height of the diffuser is higher, the performance of the diffuser augmented wind turbine will be higher. The very high and low angle of the diffuser cannot be generated the high performance of the DAWT. Therefore, the parameters of the diffuser for this diffuser augmented wind turbine should be $\mathrm{L} / \mathrm{D}=1, \mathrm{H} / \mathrm{D}=0.35$ and $\alpha=10^{\circ}$. The performance of the diffuser augmented wind turbine with the IND_009 is nearly $50 \%$ higher than that of baseline diffuser design.

\section{Outlook}

For the further investigation, Eiffel type wind tunnel (E 100-150) was already constructed at Yangon Technological University by the JICA under EEHE Project. The test section is 1000 $\mathrm{mm}$ height, $1500 \mathrm{~mm}$ width and $7500 \mathrm{~mm}$ long. The maximum wind velocity in the test section is $20 \mathrm{~m} / \mathrm{s}$. The models of the blades, rotor and diffuser have been manufactured by using the 3D printer. Experimental investigations of the horizontal axis wind turbine, the baseline diffuser augmented wind turbine, and IND_009 diffuser augmented wind turbine would be carried out in the future. Then, the performance results of the wind turbines from CFD simulations would be validated by using the experimental results.

\section{Acknowledgements}

The authors would like to express their special thanks to Daisaku Sakaguchi, Professor, Nagasaki University, Japan. Computational works were performed by the cluster computer system of graduate school of science and technology in Nagasaki University. This research was financially supported by U Nyi Hla Nge, NGE Foundation.

\section{References}

[1] Y. Ohya, and T. Karasudani. "A shrouded wind turbine generating high output power with wind-lens technology," Energies 3, Vol. 3, No. 4, pp. 634-649, 2010.

[2] O. Igra, "Compact shrouds for wind turbines," Energy Conversion, Vol. 16, No. 4, pp. 149-157, 1977.

[3] B. Kosasih, and A. Tondelli, "Experimental study of shrouded micro-wind turbine," Procedia Engineering, Vol. 49, pp. 92-98, 2012.

[4] S. Zanforlin, and S. Letizia, "Improving the performance of wind turbines in urban environment by integrating the action of a diffuser with the aerodynamics of the rooftops," Energy Procedia, Vol. 28, pp. 774-781, 2015.

[5] Y. Ohya, T. Karasudani, T. Nagai, and K. Watanabe, "Wind lens technology and its application to wind and water turbine and beyond," Renewable Energy and Environmental Sustainability, Vol. 2, p. 2, 2017.

[6] F. Sorribes-Palmer, A.Sanz-Andres, L. Ayuso, R. Sant, and S. Franchini, "Mixed CFD-1D wind turbine diffuser design optimization," Renewable energy, Vol. 105, pp. 386-399, 2017.

[7] B. Kanya, and K.D. Visser, "Experimental validation of a ducted wind turbine design strategy," Wind Energy Science, Vol. 3, No. 2, pp. 919-928, 2018.

[8] N.A. Pambudi, R. Febriyanto, K.M. Wibowo, N.D.Setyawan, N.S. Wardani, L.H. Saw, and B. Rudiyanto, "The performance of shrouded wind turbine at low wind speed condition," Energy Procedia, Vol. 158, pp. 260-265, 2019. 
[9] M. Yu Yu, and T. Min Thaw, "Design of lab-scaled horizontal axis wind turbine and numerical investigation of aerodynamics performance," Paper presented at $11^{\text {th }}$ National Conference on Science and Engineering, Yangon, Myanmar, June 2018.

[10] M. Yu Yu, and T. Min Thaw, "Aerodynamics performance of lab-scaled diffuser augmented wind turbine using numerical investigation," Paper presented at $9^{\text {th }}$ International Conference on Science and Engineering, Yangon, Myanmar, December 2018.

[11] B. Durakovic, "Design of experiments application, concepts, examples: State of the art," Periodicals of Engineering and Natural Sciences, Vol. 5, No. 3, pp. 421-439, 2017.

[12] W. Kessler, "Design of experiments - A short introduction," 6M Meeting Turin Seminar, June 2017 [PowerPoint Slides]. Retrieved from http://protecth2020.eu/wp/content/uploads/2017/06/SeminarJune14_DoE_Introduction_STZ.p df 